\title{
Composição química e valor energético de alimentos de origem animal utilizados na alimentação de codornas japonesas ${ }^{1}$
}

\author{
Marcelle Santana de Araujo ${ }^{2}$, Sergio Luiz de Toledo Barreto², Paulo Cezar Gomes², Juarez \\ Lopes Donzele ${ }^{2}$, Will Pereira de Oliveira ${ }^{2}$, Matheus Henrique Valeriano²
}

\footnotetext{
${ }^{1}$ Fonte financiadora: FAPEMIG.

${ }^{2}$ Departamento de Zootecnia/UFV.
}

RESUMO - Avaliaram-se a composição química e o valor energético de farinhas de resíduos de abatedouro para machos de codornas japonesas (Coturnix coturnix japonica). Foram utilizadas 320 codornas machos, com 32 dias de idade, distribuídas em delineamento experimental inteiramente ao acaso, com cinco dietas (uma referência e quatro dietas-teste), cada uma avaliada com oito repetições de oito aves por unidade experimental. As farinhas substituíram 25\% da dieta-referência e seus valores de energia metabolizável, assim como os coeficientes de metabolizabilidade, foram determinados pelo método de coleta total de excretas. Os valores de energia metabolizável aparente $(\mathrm{kcal} / \mathrm{kg})$ e aparente corrigida para balanço de nitrogênio (kcal/kg) são, respectivamente, de 2.152 e 2.142 para a farinha de carne e ossos; de 3.139 e 3.137 para a farinha de penas; de 2.658 e 2.651 para a farinha de peixe; e de 3.692 e 3.668 para a farinha de vísceras de aves. Os coeficientes de metabolizabilidade são de 60,51\% para farinha de carne e ossos; 59,25\% para a farinha de penas; $64,09 \%$ para farinha de peixe; e $78,64 \%$ para a farinha de vísceras de aves.

Palavras-chave: Coturnix coturnix japonica, energia, metabolizabilidade

\section{Chemical composition and energy value of food of animal origin used in diets for Japanese quails}

\begin{abstract}
It was evaluated the chemical composition and energy values of slaughterhouse by-product meal for male Japanese quails (Coturnix coturnix japonica). It was used 320 male quails at 32 days of age, distributed in a complete random experimental design, with five diets (one reference diet and four test diets), each one evaluated with eight replicates with eight birds per experimental unity. Meals replaced 25\% of the reference diet and their metabolizable energy values as well as their metabolizability coefficients were determined by using the total excreta method collection. Values of apparent metabolizable energy $(\mathrm{kcal} / \mathrm{kg})$ and apparent energy corrected for nitrogen balance $(\mathrm{kcal} / \mathrm{kg})$ are, respectively, 2,152 and 2,142 for meat and bone meal; 3,139 and 3,137 for feather meal; 2,658 and 2,651 for fish meal and 3,692 and 3,668 for poultry viscera meal. Metabolizability coefficients are $60.51 \%$ for meat and bone meal; 59.25\% for feather meal; $64.09 \%$ for fish meal and $78.64 \%$ for poultry viscera meal.
\end{abstract}

Key Words: Coturnix coturnix japonica, metabolizability, energy

\section{Introdução}

Ao longo dos anos, os estudos voltados à nutrição e alimentação animal possibilitaram aos profissionais utilizar diversos ingredientes para atender às exigências nutricionais de aves, de modo a permitir a manutenção das funções bioquímicas normais e expressão máxima de desempenho produtivo.

De acordo com vários autores, o balanceamento adequado de rações só é possível a partir do conhecimento da composição química e do conteúdo energético dos ingredientes (Generoso et al., 2008; Calderano et al., 2010).
Energia é todo produto resultante de processos oxidativos dos componentes orgânicos dos alimentos, portanto não é caracterizada como nutriente (Nascimento et al., 2002; Silva et al., 2003). O conteúdo energético ou o valor da energia metabolizável (EM) de uma ração é inversamente relacionado à ingestão de alimentos e constitui fator limitante para o consumo de ração pelas aves (Rodrigues et al., 2002; Silva et al., 2003). A porção em energia é expressa em kcal de EM em relação à 1 kg de ração.

Os alimentos de origem animal, como farinhas oriundas das atividades de abate e do processamento das carnes, apresentam variações na composição química e nos valores 
de energia metabolizável (Vieites et al., 2000; Nascimento et al., 2002; Nunes et al., 2005; Brumano et al., 2006), devido a fatores como tipo de processamento, condições de armazenamento e forma de obtenção, que podem justificar alterações nos valores de energia metabolizável. A utilização de alimentos alternativos na formulação de rações é importante para redução dos custos com alimentação e dos efeitos poluentes da água e do solo (Nunes et al., 2005).

O estudo do valor nutricional e energético das matériasprimas deve ser constante, como forma de atualizar as tabelas de composição de alimentos (Nery et al., 2007) e tornar ampliar as opções de alimentos alternativos (Generoso et al., 2008). Entretanto, aspectos inerentes aos alimentos não são os únicos responsáveis pela variabilidade dos resultados de energia metabolizável. A metodologia experimental e as características relativas à espécie animal também influenciam no valor energético do alimento (Silva et al., 2003). Em trabalhos realizados por Furlan et al. (1998), Murakami \& Furlan et al. (2002), Silva et al. (2003), Sakamoto et al. (2006) e Gomes et al. (2007), destacam-se características fisiológicas relativas ao trato gastrointestinal e ao tempo de passagem do bolo alimentar como fatores importantes para o aproveitamento dos nutrientes e do conteúdo energético dos alimentos em codornas, portanto, são relevantes na determinação dos valores de energia metabolizável.

Assim, é essencial investigar os valores de energia metabolizável dos alimentos para cada espécie de interesse zootécnico. Desse modo, objetivou-se neste estudo determinar a composição química, os valores de energia metabolizável aparente e aparente corrigida pelo balanço de nitrogênio e calcular os coeficientes de metabolizabilidade da energia bruta de alguns alimentos de origem animal em codornas japonesas.

\section{Material e Métodos}

Realizou-se um ensaio de metabolismo no Setor de Avicultura do Departamento de Zootecnia da Universidade Federal de Viçosa, Minas Gerais, no período de 17/6/2006 a 21/8/2006 utilizando-se o método tradicional de coleta total de excretas. Utilizaram-se 320 machos de codornas japonesas com 32 dias de idade, distribuídos em delineamento experimental inteiramente ao acaso, com cinco tratamentos, oito repetições e oito aves por unidade experimental.

$\mathrm{Na}$ fase inicial, as aves receberam ração formulada segundo as recomendações do NRC (1994) e foram alojadas em instalação de alvenaria com piso coberto com maravalha.

Ao completarem a 20 dias de idade e peso corporal de $82,50 \pm 3,48 \mathrm{~g}$, as aves foram transferidas para baterias de estrutura metálica de cinco andares e três unidades experimentais por andar, totalizando 15 compartimentos de $96 \times 37 \times 16 \mathrm{~cm}$ (largura $\times$ profundidade $\times$ altura), com comedouro de metal galvanizado, bebedouro tipo calha de PVC (policloreto de vinila) e bandeja encapada com lona plástica para coleta das excretas. Foram utilizadas três baterias (B1, B2 e B3) e, para que não houvesse interferência quanto à disposição das unidades experimentais, a bateria B1 foi ocupada de modo que a gaiola do canto direito inferior ficasse desocupada. As baterias B2 e B3 foram totalmente ocupadas, com exceção das gaiolas do canto inferior direito, e a do meio referente ao último andar, de cima para baixo. As aves receberam água e ração experimental à vontade durante dez dias, cinco dias para adaptação e cinco para coleta total das excretas, que foram realizadas duas vezes ao dia, às $8 \mathrm{~h}$ e às $17 \mathrm{~h}$, para evitar fermentação. A quantidade de ração consumida, equivalente aos cinco dias de coleta, foi calculada descontando-se as sobras, do comedouro e do balde, da quantidade de ração pesada no início do experimento, para cada unidade experimental.

As excretas foram acondicionadas em sacos plásticos identificados e armazenadas em freezer até o final do período de coleta. Ao término do experimento, foram descongeladas, pesadas e homogeneizadas retirando-se amostras para análises laboratoriais.

Os alimentos avaliados foram farinha de carne e ossos; farinha de penas; farinha de peixe; e farinha de vísceras de aves; e uma ração-referência (Tabela 1), formulada para atender às exigências nutricionais de codornas em fase inicial preconizadas pelo NRC (1994). A composição das rações-teste foi de $25 \%$ do alimento avaliado adicionados a 75\% da ração-referência.

A temperatura foi medida por meio de termômetros de máxima e de mínima, mantidos à altura média das baterias e posicionados no centro da sala.

A análise de composição química dos alimentos, da ração-referência e das excretas foi realizada no Laboratório de Nutrição Animal do Departamento de Zootecnia da Universidade Federal de Viçosa, segundo técnicas descritas por Silva \& Queiroz (2002).

Os valores de energia metabolizável (aparente $=\mathrm{EMA} \mathrm{e}$ aparente corrigida $=$ EMAn) foram calculados utilizando-se as equações propostas por Sakomura \& Rostagno (2007) e os coeficientes de metabolizabilidade da energia bruta ( aparente $=\mathrm{CMEB}$ e aparente corrigida $=\mathrm{CMEBn}$ ), obtidos a partir da porcentagem de energia bruta convertida em EMA comparados pelo teste SNK, a 5\% de probabilidade, utilizando-se o programa SAEG - Sistema de Análise Estatística e Genética (UFV, 2005). 
Tabela 1 - Composição percentual da ração-referência e das rações-teste, na matéria natural

\begin{tabular}{|c|c|c|c|c|c|}
\hline Ingrediente (\%) & \multicolumn{5}{|c|}{ Ração-teste } \\
\hline Farelo de soja & 43,90 & 32,93 & 32,93 & 32,93 & 32,93 \\
\hline Óleo de soja & 2,49 & 1,87 & 1,87 & 1,87 & 1,87 \\
\hline Fosfato bicálcico & 1,70 & 1,28 & 1,28 & 1,28 & 1,28 \\
\hline DL-metionina (99\%) & 0,15 & 0,11 & 0,11 & 0,11 & 0,11 \\
\hline L-treonina $(97 \%)$ & 0,10 & 0,08 & 0,08 & 0,08 & 0,08 \\
\hline Suplemento vitamínico ${ }^{1}$ & 0,10 & 0,07 & 0,07 & 0,07 & 0,07 \\
\hline Suplemento mineral ${ }^{2}$ & 0,05 & 0,04 & 0,04 & 0,04 & 0,04 \\
\hline Coccidiostático $^{3}$ & 0,05 & 0,04 & 0,04 & 0,04 & 0,04 \\
\hline Cloreto de colina (60\%) & 0,04 & 0,03 & 0,03 & 0,03 & 0,03 \\
\hline Energia metabolizável (kcal/kg) & 2.900 & 2.659 & 2.828 & 2.832 & 2.990 \\
\hline Proteína bruta (\%) & 24,00 & 28,66 & 36,43 & 31,55 & 30,84 \\
\hline Metionina + cistina total (\%) & 0,89 & 0,87 & 1,60 & 1,25 & 1,17 \\
\hline Metionina + cistina digestível (\%) & 0,80 & 0,75 & 1,15 & 1,10 & 0,99 \\
\hline Lisina total $(\%)$ & 1,35 & 1,49 & 1,57 & 1,85 & 1,84 \\
\hline Lisina digestível (\%) & 1,21 & 1,33 & 1,33 & 1,66 & 1,58 \\
\hline Treonina total $(\%)$ & 1,04 & 0,78 & 1,64 & 1,29 & 1,31 \\
\hline Treonina digestível (\%) & 0,92 & 0,91 & 1,33 & 1,19 & 1,17 \\
\hline Triptofano total (\%) & 0,32 & 0,28 & 0,36 & 0,34 & 0,37 \\
\hline Triptofano digestível (\%) & 0,28 & 0,25 & 0,31 & 0,31 & 0,32 \\
\hline Cálcio (\%) & 1,04 & 3,33 & 0,80 & 2,35 & 2,16 \\
\hline Fósforo disponível (\%) & 0,43 & 2,02 & 0,51 & 1,04 & 0,99 \\
\hline
\end{tabular}

\section{Resultados e Discussão}

As temperaturas médias mínima e máxima durante a fase experimental foram $19,3^{\circ} \mathrm{C} \pm 1,20$ e $24,6^{\circ} \mathrm{C} \pm 2,24$, respectivamente. A composição química dos alimentos avaliados (Tabela 2) diferiu daquela descrita por Rostagno et al. (2005), comprovando variação nos valores nutricionais desses alimentos.

Os teores de proteína bruta da farinha de peixe e da farinha de vísceras de aves foram inferiores aos valores propostos por Rostagno et al. (2005), enquanto os valores determinados nos demais alimentos foram superiores aos reportados por esses autores. Os valores de extrato etéreo foram semelhantes, ou maiores, para maioria dos alimentos, com exceção da farinha de carne e ossos, cujo valor foi 15,13\% inferior àquele descrito por Rostagno et al. (2005). A variação no conteúdo de matéria mineral foi pequena em relação aos valores citados por Rostagno et al. (2005), exceto para farinha de vísceras de aves e de carne e ossos. As diferenças no teor de cálcio dos alimentos, em comparação ao valor citado por Rostagno et al. (2005), foram mais evidentes para farinha de penas $(0,21 \%$ vs $0,36 \%)$. No entanto, Nunes et al. (2005) determinaram na farinha de penas valores de $0,16 \%$ de cálcio. Os alimentos apresentaram diferenças no teor de fósforo total em comparação aos dados publicados por Rostagno et al. (2005).

As farinhas de carne e ossos; de peixe; e de vísceras de aves foram inferiores, em fósforo total às farinhas analisadas por Vieites et al. (2000), Brumano et al. (2006) e Nunes et al. (2005). A farinha de penas avaliada neste trabalho apresentou $42,50 \%$ de fósforo total, valor superior àqueles descritos por Nunes et al. (2005). As farinhas de penas, de peixe e de vísceras de aves foram os alimentos que mais diferiram daqueles citados por Rostagno et al. (2005) quanto ao teor de extrato não-nitrogenado. A composição em extrato etéreo foi responsável pelas diferenças entre as farinhas. No caso da farinha de vísceras, os altos valores 
Tabela 2 - Composição química e valores de energia bruta dos alimentos, na matéria natural ${ }^{1}$

\begin{tabular}{|c|c|c|c|c|}
\hline & \multicolumn{4}{|c|}{ Alimento } \\
\hline & Farinha de carne e ossos & Farinha de penas & Farinha de peixe & Farinha de vísceras de aves \\
\hline Matéria seca & 87,75 & 90,03 & 88,19 & 91,53 \\
\hline Proteína bruta & 42,65 & 73,70 & 54,19 & 51,36 \\
\hline Extrato etéreo & 9,37 & 8,92 & 9,02 & 15,21 \\
\hline Matéria mineral & 34,14 & 2,79 & 22,00 & 20,95 \\
\hline Cálcio & 10,31 & 0,21 & 6,39 & 5,63 \\
\hline Fósforo total & 4,67 & 0,40 & 1,13 & 0,94 \\
\hline Extrato não-nitrogenado & 1,58 & 4,62 & 5,41 & 4,00 \\
\hline Energia bruta (kcal/kg) & 3.539 & 5.295 & 4.136 & 4.508 \\
\hline
\end{tabular}

desse nutriente e de matéria mineral foram o fator que mais influenciou o baixo valor de extrato não-nitrogenado em comparação aos dados descritos por Rostagno et al. (2005). O valor de energia bruta da farinha de carne e ossos foi superior em $253 \mathrm{kcal} / \mathrm{kg}$ e a farinha de vísceras, inferior em $153 \mathrm{kcal} / \mathrm{kg}$ aos valores citados por Rostagno et al. (2005). O valor da farinha de vísceras avaliada foi $647 \mathrm{kcal} / \mathrm{kg}$ superior ao relatado por Nunes et al. (2005).

As matérias-primas utilizadas na composição dos alimentos de origem animal e a falta de padronização, em decorrência de fatores operacionais e dos constituintes, é a possível causa das diferenças na composição química dos alimentos avaliados neste estudo em relação àquela descrita na literatura.

Entre os alimentos avaliados, a farinha de carne e ossos foi o que teve menor valor de EMAn (Tabela 3), enquanto a farinha de vísceras de aves foi superior quanto a esse parâmetro. Esses achados são similares àqueles descritos por Rostagno et al. (2005). Os resultados encontrados para EMAn da farinha de carne e ossos foram superiores àqueles relatados por Rostagno et al. (2005) e inferiores as descritos por Gomes et al. (2007). O coeficiente de metabolizabilidade aparente corrigido da farinha de carne e ossos diferiu em 2,58\% daqueles determinados por Rostagno et al. (2005) em frangos de corte e em 18,30\% dos resultados estimados por Gomes et al. (2007) para codornas japonesas em postura com 19 semanas de idade.

A idade das aves e o tipo de processamento dos alimentos de origem animal podem causar diferenças nos resultados, tanto para valores de energia metabolizável aparente quanto para o coeficiente de metabolizabilidade da energia bruta. O valor de energia metabolizável aparente corrigido determinado para farinha de penas foi maior que todos aqueles citados na literatura (Nery et al., 2007; Santos et al., 2006; Rostagno et al., 2005; Nunes et al., 2005): foi superior em 19,57 e 12,24\% aos dados observados por Nery et al. (2007) para dois tipos de farinha de penas e em 16,77\% em relação ao valor citado por Rostagno et al. (2005). Santos et al. (2006), em ensaio com codornas de corte machos aos 35 dias de idade, também determinaram valores menores para a farinha de penas ( $2.642 \mathrm{kcal} / \mathrm{kg}$ ). É possível que a farinha de penas, por ser processada e oriunda de abatedouros, seja um produto contaminado com sangue, o que resultaria em aumento dos valores de EMAn. O resultado encontrado para o coeficiente de metabolizabilidade da energia bruta corrigido da farinha de penas foi maior que aquele verificado por Nery et al. (2007), que observaram, em média, valor de 50,59\% para as duas farinhas estudadas; por Santos et al. (2006), de 51,94\%; e por Nunes et al. (2005), de $55,18 \%$.

O valor de energia metabolizável aparente corrigida da farinha de peixe foi semelhante (2.651 vs $2.627 \mathrm{kcal} / \mathrm{kg}$ ) ao relatado por Rostagno et al. (2005), entretanto foi superior em 7,47\% ao descrito por Silva et al. (2003) para codornas japonesas. Os valores calculados para o coeficiente de metabolizabilidade da energia bruta corrigidos da farinha de peixe se aproximaram mais dos descritos por Rostagno et al. (2005) para frangos de corte $(63,85 \%)$ que os relatados por Silva et al. (2003) para codornas (57,57\%). Para a farinha de vísceras de aves, o resultado de energia metabolizável

Tabela 3 - Energia metabolizável e coeficiente de metabolizabilidade aparente da energia dos alimentos, expressos na matéria natural

\begin{tabular}{|c|c|c|c|c|}
\hline & \multicolumn{4}{|c|}{ Alimento } \\
\hline & $\begin{array}{c}\text { Farinha de } \\
\text { carne e ossos }\end{array}$ & $\begin{array}{l}\text { Farinha } \\
\text { de penas }\end{array}$ & $\begin{array}{l}\text { Farinha } \\
\text { de peixe }\end{array}$ & $\begin{array}{c}\text { Farinha de } \\
\text { vísceras de aves }\end{array}$ \\
\hline Energia metabolizável aparente (kcal/kg) & $2.152 \pm 142,61$ & $3.139 \pm 217,21$ & $2.658 \pm 196,50$ & $3.565 \pm 425,58$ \\
\hline Energia metabolizável aparente corrigida (kcal/kg) & $2.142 \pm 140,28$ & $3.137 \pm 191,43$ & $2.651 \pm 195,06$ & $3.545 \pm 412,90$ \\
\hline Coeficiente de metabolizabilidade da energia bruta $(\%)^{1}$ & $60,82 \pm 4,03 \mathrm{~B}$ & $59,29 \pm 3,71 \mathrm{~B}$ & $64,26 \pm 4,75 \mathrm{~B}$ & $79,08 \pm 9,44 \mathrm{~A}$ \\
\hline Coeficiente de metabolizabilidade da energia bruta corrigido (\%) ${ }^{1}$ & $60,51 \pm 3,96 \mathrm{~B}$ & $59,25 \pm 3,62 B$ & $64,09 \pm 4,72 B$ & $78,64 \pm 9,16 \mathrm{~A}$ \\
\hline
\end{tabular}

${ }^{1}$ Médias seguidas por letras diferentes na linha, diferem entre si pelo teste Student Newman-Keuls a $1 \%$ de probabilidade. 
aparente corrigido foi superior, em 8,06 e 21,27\%, respectivamente, àqueles relatados por Rostagno et al. (2005) e Silva et al. (2003). No caso da farinha de vísceras de aves, foi maior que os relatados por Nunes et al. (2006) para três tipos de farinha de vísceras de aves determinados com frangos de corte aos 21 dias de idade (2.750, 2.713 e $3.069 \mathrm{kcal}$ de EMAn/kg); e por Santos et al. (2006), em machos de codornas de corte aos 35 dias de idade, de $2.665 \mathrm{kcal} / \mathrm{kg}$. O coeficiente de metabolizabilidade aparente corrigido da energia bruta foi maior que aqueles publicados por Santos et al. (2006), que relataram valor de 58,12\%; por Rostagno et al. (2005), de 69,92\%; por Silva et al. (2003), de 65,0\%; e por Nunes (2003), de 67,21\%.

A variação entre resultados descritos na literatura confirma a importância desse estudo e da avaliação energética e química de alimentos alternativos, principalmente os de origem animal, tendo em vista a influência na formulação de dietas e no desempenho de diversas espécies de interesse zootécnico.

\section{Conclusões}

Os valores de energia metabolizável aparente corrigida para codornas japonesas machos são de $2.142 \mathrm{kcal} / \mathrm{kg}$ para farinha de carne e ossos; $3.137 \mathrm{kcal} / \mathrm{kg}$ para farinha de penas; $2.651 \mathrm{kcal} / \mathrm{kg}$ para farinha de peixe; e de 3.545 para a farinha de vísceras de aves. Os coeficientes de metabolizabilidade da energia bruta são de 60,51\% para farinha de carne e ossos; 59,25\% para farinha de penas; de 64,09\% para farinha de peixe; e 78,64 para farinha de vísceras de aves.

\section{Agradecimentos}

À Fundação de Amparo à Pesquisa do Estado de Minas Gerais - FAPEMIG, pelo financiamento do projeto de pesquisa.

\section{Referências}

BRUMANO, G.; GOMES, P.C.; ALBINO, L.F.T. Composição química e valores de energia metabolizável de alimentos protéicos determinados com frangos de corte em diferentes idades. Revista Brasileira de Zootecnia, v.35, n.6, p.22972302, 2006.

CALDERANO, A.A.; GOMES, P.C.; ALBINO, L.F.T. et al. Composição química e energética de alimentos de origem vegetal determinada em aves de diferentes idades. Revista Brasileira de Zootecnia, v.39, n.2, p.320-326, 2010.
FURLAN, A.C.; ANDREOTTI, M.O.; MURAKAMI, A.E. et al. Valores energéticos de alguns alimentos determinados com codornas japonesas (Coturnix coturnix japonica). Revista Brasileira de Zootecnia, v.27, n.6, p.1147-1150, 1998.

GENEROSO, R.A.R.; GOMES, P.C.; ROSTAGNO, H.S. et al. Composição química e energética de alguns alimentos para aves em duas idades. Revista Brasileira de Zootecnia, v.37, n.7, p.1251-1256, 2008.

GOMES, F.U.; FASSANI, E.J.; RODRIGUES, P.B. et al. Valores energéticos de alguns alimentos utilizados em rações para codornas japonesas. Revista Brasileira de Zootecnia, v.36, n.2, p.396-402, 2007.

MURAKAMI, A.E.; FURLAN, A.C. Pesquisa na nutrição e alimentação de codornas em postura no Brasil. In: SIMPÓSIO INTERNACIONAL DE COTURNICUlTURA, 1., 2002, Lavras. Anais... Lavras: Universidade Federal de Lavras, 2002. p.113-120.

NASCIMENTO, A.H.; GOMES, P.C.; ALBINO, L.F.T. et al. Composição química e valores de energia metabolizável das farinhas de penas e vísceras determinados por diferentes metodologias para aves. Revista Brasileira de Zootecnia, v.31, n.3, p.1409-1417, 2002.

NATIONAL RESERCH COUNCIL - NRC. Nutrient requirements of poultry. 9.ed. Washington: National Academy of Sciences, 1994. p.155.

NERY, L.R.; ALBINO, L.F.T.; ROSTAGNO H.S. et al. Valores de energia metabolizável de alimentos determinados com frangos de corte. Revista Brasileira de Zootecnia, v.36, n.5, p.1354-1358, 2007.

NUNES, R.V.; ROSTAGNO, H.S.; GOMES, P.C. et al. Valores energéticos de diferentes alimentos de origem animal para aves. Revista Brasileira de Zootecnia, v.35, n.4, p.1752-1757, 2006.

NUNES, R.V.; POZZA, P.C.; NUNES, C.G.V. et al. Valores energéticos de subprodutos de origem animal para aves. Revista Brasileira de Zootecnia, v.34, n.4, p.1217-1224, 2005.

RODRIGUES, P.B.; ROSTAGNO, H.S.; ALBINO, L.F.T. et al. Valores energéticos da soja e subprodutos da soja, determinados com frangos de corte e galos cecectomizados. Revista Brasileira de Zootecnia, v.31, n.4, p.1771-1782, 2002.

ROSTAGnO, H.S. Tabelas brasileiras para aves e suínos: composição de alimentos e exigências nutricionais. 2.ed. Viçosa, MG: UFV, Departamento de Zootecnia, 2005. 186p.

SAKAMOTO, M.I.; MURAKAMI, A.E.; SOUZA, L.M.G et al. Valor energético de alguns alimentos alternativos para codornas japonesas. Revista Brasileira de Zootecnia, v.35, n.3, p.818-821, 2006.

SAKOMURA, N.K. \& ROSTAGNO, H.S. Métodos de pesquisa em nutrição de monogástricos. Jaboticabal: Funep, 2007. 283p.

SANTOS, A.L.S.; GOMES, A.V.C.; PESSOA, M.F. et al. Composição química e valores energéticos de fontes protéicas em codornas de corte em diferentes idades. Revista Ciência Rural, v.36, n.3, p.930-935, 2006.

SILVA, D.J.; QUEIROZ, A.C. Análise de alimentos (métodos químicos e biológicos). $1^{\circ}$ reimpressão. Viçosa, MG: UFV, Imprensa Universitária, 2002. 235p.

SILVA, J.H.V.; SILVA, M.B.; SILVA, E.L. et al. Energia metabolizável de ingredientes determinada com codornas japonesas (Coturnix coturnix japonica). Revista Brasileira de Zootecnia, v.32, n.6, p.1912-1918, 2003 (supl.2).

UNIVERSIDADE FEDERAL DE VIÇOSA - UFV. Central de Processamento de Dados - UFV/CPD. SAEG - Sistema para análises estatísticas. Versão 9.1. Viçosa, MG, 301p., 2005.

VIEITES, F.M.; ALBINO, L.F.T.; SOARES, P.R. et al. Valores de energia metabolizável aparente da farinha de carne e ossos para aves. Revista Brasileira de Zootecnia, v.29, n.6, p.2292-2299, 2000. 